\title{
The impact of FDI on environmental technology innovation from the perspective of environmental regulation
}

\author{
Ziting Wei ${ }^{1, *}$ \\ ${ }^{1}$ School of economics and management, Beijing JiaoTong University, Beijing, 100044, China
}

\begin{abstract}
Based on the perspective of environmental regulation, this paper selects panel data of 30 provinces in China from 2011 to 2016, establishes Hansen panel threshold regression model, and investigates the impact of FDI on environmental technology innovation of industrial enterprises in China under the threshold of environmental regulation. The results show that FDI has a significant inhibitory effect on the environmental technological innovation of industrial enterprises; the effect has a significant dual threshold of environmental regulation, with the intensity of environmental regulation across the threshold, the negative impact of FDI gradually weakened; market demand and industry scale have a significant positive impact, the role of technological progress is not significant.The findings of this paper provide a certain reference for the rational use of environmental regulation policies, the maximization of FDI technology spillover, the promotion of environmental technology innovation of industrial enterprises, and the realization of "win-win" of environment and economy.
\end{abstract}

\section{Introduction}

With the rapid development of economy, environmental problems have also emerged, which has attracted the attention of the society and the government. Reducing enterprises' pollutant emissions and realizing green transformation have become the key to solve China's environmental problems. Environmental technology innovation is the basis of Porter's hypothesis. Therefore, it is one of the important ways to promote industrial enterprises to improve the ability of environmental technology innovation. On the one hand, China still needs FDI. On the other hand, due to the externality of environmental technology innovation, enterprises will consider the adoption of technologies related to environmental protection only through external factors such as environmental policies ${ }^{[1]}$. Therefore, environmental regulation policy is a necessary factor affecting enterprise environmental technology innovation. Under different environmental regulation intensity, FDI may have different effects on environmental technology innovation of enterprises.

In view of this, this paper selets the provincial panel data of China from 2011 to 2016, uses python to obtain the industrial enterprise environmental technology patent application quantity, constructs the environmental regulation index, and investigates the threshold effect of environmental regulation in FDI on the environmental technology innovation of industrial enterprises.

On the one hand, indicators are often selected to instead the patent, which may affect the accuracy of the results; on the other hand, most of the previous studies are often from the perspective of human capital level and regional economic level, or directly studied the impact of environmental regulation on technological innovation, but ignored the comprehensive impact. This paper comprehensively considers FDI and environmental regulation, and makes empirical test on the threshold value of environmental regulation, which can provide countermeasures and suggestions for the rational use of environmental regulation policies, maximize the technology spillover of FDI, promote environmental technology innovation, and realize the "win-win" of environment and economy.

\section{Literature review and assumptions}

FDI may affect environmental technology innovation of industrial enterprises through competition effect, technology spillover and "pollution haven" effect. Among them, the competitive effect refers to that some FDI enterprises with advanced technology, high productivity and low cost will "force" the host country's enterprises to carry out technological innovation; technology spillover refers to the external effect that multinational companies implement FDI in the host country, which leads to the progress of local technology or productivity, while the multinational companies cannot obtain all the benefits ${ }^{[2]}$; and the "pollution haven" effect means that developing countries relax environmental regulations in order to attract FDI, so as to attract more pollution intensive FDI and hinder environmental technology innovation ${ }^{[3]}$. Although there may be a positive impact, more and more literatures show that FDI can play a negative role in promoting technology spillover, and there may be threshold effects

\footnotetext{
* Corresponding author: 18120551@bjtu.edu.cn
} 
such as intellectual property protection. When FDI crosses the threshold value, its effect on technological innovation will change from negative to positive. Based on this, we propose hypothesis 1: FDI has a negative impact on environmental technology innovation of industrial enterprises.

Environmental regulation may weaken the inhibitory effect on environmental technology innovation of industrial enterprises. The improvement of innovation capability mainly comes from independent R\&D and international spillover. However, due to the existence of "pollution shelter" and other effects, FDI may have a negative effect on China's innovation ability. According to Porter's hypothesis, setting up reasonable environmental regulation policies can stimulate enterprises to carry out technological innovation, and then enhance the ability of environmental technology innovation. Therefore, environmental regulation may alleviate the negative effects of FDI. When the level of environmental regulation is low, the technological content and clean level of FDI spillover results are limited, and the improvement of industrial enterprises' environmental technology innovation ability is also limited; When the level of environmental regulation is high, more stringent environmental policies may play a "screening" role on FDI enterprises and "force" FDI enterprises to be more cautious Through the absorption and secondary innovation of industrial enterprises, the innovation ability of environmental technology can be improved. Based on this, we propose hypothesis 2: FDI has the threshold effect of environmental regulation on environmental technology innovation of enterprises.

\section{Empirical strategy}

\subsection{Model setting}

This paper uses the nonlinear panel threshold regression model of Hansen to investigate the environmental regulation threshold effect of FDI on the environmental technology innovation of industrial enterprises. The basic model is set as follows.

$$
\begin{aligned}
& \ln \text { pat }_{i t}=\alpha_{1} \ln f d i_{i t} \cdot I\left(\ln e r_{i t} \leq \gamma\right)+ \\
& \alpha_{2} \ln f d i_{i t} \cdot I\left(\ln e r_{i t}>\gamma\right)+\beta \ln x_{i t}+\mu_{i}+\varepsilon_{i t}
\end{aligned}
$$

In formula (1), pat it is the explained variable, indicating the number of industrial environmental technology patent applications of the province $i$ in $t$; $f d i_{i t}$ is the core explanatory variable, representing the province $i$ 's FDI in $t ; e r_{i t}$ is the threshold variable, indicating the level of environmental regulation of the province $i$ in $t ; x_{i t}$ represents some control variables of the province, including the turnover of $R \& D$ investment technology, market turnover and annual industrial output value of enterprises above designated size in the industry; $\varepsilon_{i t}$ is the error term, $\varepsilon_{i t} \sim \operatorname{iid}\left(0, \sigma^{2}\right)$; and $\mu_{i}$ represents the individual effect of each sample cross section which does not change with time; $I(*)$ represents an indicator function, when the conditions in brackets are satisfied, the value is 1 , otherwise, the value is 0 .

Model (1) is a single threshold model. Considering that there may be multiple thresholds, we establish a "double threshold effect" mode, which is shown in formula (2).

$$
\begin{aligned}
& \ln \mathrm{pat}_{i t}=\alpha_{1} \ln f d i_{i t} \cdot I\left(\ln e r_{i t} \leq \gamma_{1}\right)+\alpha_{2} \ln f d i_{i t} \cdot I\left(\gamma_{1}<\right. \\
& \left.\ln e r_{i t} \leq \gamma_{2}\right)+\alpha_{3} \ln f d i_{i t} \cdot I\left(\ln e r_{i t}>\gamma_{2}\right)+\beta \ln x_{i t}+\mu_{i}+\varepsilon_{i t}
\end{aligned}
$$

\subsection{Variable setting and data source}

This paper selects the data of 30 provinces in China except Tibet from 2011 to 2016, and uses stata13.0 measurement software for data analysis and model regression. The relevant variables are as follows.

Explained variable: Environmental technological innovation of industrial enterprises ( pat). Although the number of patents can not reflect all innovation, patent is still the most commonly used indicator to measure innovation capability because of its universality, consistency and accessibility ${ }^{[4]}$. Moreover, the patent application and acceptance process of each province in China are consistent, and the patent data are comparable, so this paper uses the method of Zhang Yanbo et al. ${ }^{[1]}$ to measure the environmental technology innovation of industrial enterprises. We use Python statements to filter. The relevant data comes from the "patent technology database" in Wanfang database.

(2) Core explanatory variable: Foreign Direct Investment $(f d i)$. In this paper, the ratio of the amount of foreign direct investment actually used by each region to GDP after being converted into RMB is used as the proxy variable. The relevant data is from China Urban Statistical Yearbook (2012-2017).

(3) Threshold variable: environmental regulation $(e r)$. There is no unified standard for the quantitative indicators of formal environmental regulation. The measurement methods in the existing literature can be divided into single index method, comprehensive index method, classification inspection method and evaluation scoring method. Integrating the advantages and disadvantages of various indicators and data availability, this paper uses the method of Shen Neng and Liu Fengchao $^{[5]}$ for reference to construct the environmental regulation evaluation index. The advantage of this method is that the influence of industrial structure factors is removed from the environmental regulation index, and the deviation caused by the difference of industrial structure on the evaluation of environmental regulation intensity is reduced ${ }^{[6]}$. The specific tectonic process is shown in formula (3).

$$
e r_{i t}=\left(\text { Investment }_{i t} / \text { Value }_{i t}\right) / \text { Industrial }_{i t}
$$

In formula (3), er $r_{i t}$, Investment ${ }_{i t}$, Value $_{i t}$, Industrial $_{i t}$, respectively represent the intensity of environmental regulation, the completion of industrial pollution investment, the industrial added value and the proportion of industrial added value in GDP. The relevant data is from the website of National Bureau of statistics. 
(4) Control variables: in order to obtain unbiased estimation results, some other variables are set in this paper.

Technological progress $(r d)$ is represented by the internal expenditure of $\mathrm{R} \& \mathrm{D}$ funds of industrial enterprises above the provincial scale. The deflator is composed of fixed assets investment price index and consumer price index weighted, and the base period is 2011. The relevant data is from the statistical yearbook of each province.

Market demand pull ( $j s$ ) is represented by the transaction volume of provincial technology markets after the adjustment of the ex factory price index of industrial products. The relevant data is from the website of the National Bureau of statistics.

Industry size $(z y)$ is represented by the main business income of industrial enterprises above designated size in each province after the adjustment of the ex factory price index of industrial products. The relevant data is from China Science and Technology Statistical Yearbook (2012-2017).

\section{Empirical results and analysis}

By ADF test and Hausmann test, the data in this paper are stationary series and this paper is suitable for double fixed effect model. Model 1 in Table 2 is the regression result of fixed effect model. It can be seen that the estimated coefficient of FDI is significantly negative, which indicates that China's FDI has an inhibitory effect on environmental technology innovation of industrial enterprises, which may be due to the "pollution haven" effect of China's current FDI.

In order to further reveal whether the inhibitory effect of FDI on enterprise's environmental technology innovation is alleviated under the restriction of environmental regulation, this paper uses Hansen's panel threshold regression method to estimate. Table 1 shows the results of threshold existence test and its estimated value, including the model with and without control variable, and two models for robustness test. Robustness test 1 excludes 2011 and uses 2012-2016 as the research period; robustness test 2 excludes four municipalities directly under the central government. It can be seen that the single threshold and double threshold effects of environmental regulation are significant at the $5 \%$ significance level, indicating that the double threshold test selected in this paper is more reliable.

Table 1. Threshold effect test results

\begin{tabular}{|c|c|c|c|c|c|}
\hline Model & $\begin{array}{l}\text { Threshol } \\
\text { dnumber }\end{array}$ & $\begin{array}{l}\text { Estimate-d } \\
\text { value }\end{array}$ & F value & $\begin{array}{c}\mathbf{P} \\
\text { value }\end{array}$ & $\begin{array}{l}\text { BS } \\
\text { times }\end{array}$ \\
\hline \multirow{2}{*}{$\begin{array}{c}\text { Contains } \\
\text { control } \\
\text { variables }\end{array}$} & $\begin{array}{c}\text { Single } \\
\text { threshold }\end{array}$ & 4.400 & $27.43 * * *$ & 0.000 & 300 \\
\hline & $\begin{array}{c}\text { Double } \\
\text { threshold }\end{array}$ & 5.729 & $16.80 * *$ & 0.030 & 300 \\
\hline \multirow{2}{*}{$\begin{array}{c}\text { Contains } \\
\text { no } \\
\text { control } \\
\text { variables }\end{array}$} & $\begin{array}{c}\text { Single } \\
\text { threshold }\end{array}$ & 4.400 & $38.71 * *$ & 0.020 & 300 \\
\hline & $\begin{array}{c}\text { Double } \\
\text { threshold }\end{array}$ & 5.628 & $22.18 * *$ & 0.030 & 300 \\
\hline \multirow{2}{*}{$\begin{array}{l}\text { Robustn } \\
\text { ess test } 1\end{array}$} & $\begin{array}{c}\text { Single } \\
\text { threshold }\end{array}$ & 4.400 & $36.74 * * *$ & 0.000 & 300 \\
\hline & $\begin{array}{c}\text { Double } \\
\text { threshold }\end{array}$ & 5.671 & $21.63 * *$ & 0.012 & 300 \\
\hline
\end{tabular}

\begin{tabular}{|c|c|c|c|c|c|}
\hline Robustn & $\begin{array}{c}\text { Single } \\
\text { threshold }\end{array}$ & 4.351 & $23.18^{* * *}$ & 0.007 & 300 \\
\cline { 2 - 6 } & $\begin{array}{c}\text { Double } \\
\text { threshold }\end{array}$ & $5.729 * *$ & $18.47 * *$ & 0.037 & 300 \\
\hline
\end{tabular}

Note: $* * * * *$ and $*$ are significant at $1 \%, 5 \%$ and $10 \%$ levels.

Table 2 shows the estimated results of panel model. Model 2 does not consider control variables, model 3 considers control variables, model 4 and model 5 are the results of robustness test. Compared with the results of linear model and nonlinear model, it is found that the influence direction of each variable is consistent, which proves the robustness of regression. From model 3, we can see that environmental regulation has double threshold effect in the impact of FDI. When the intensity of environmental regulation is increased until the first threshold is crossed, the coefficient of FDI increases significantly; when the second threshold is crossed, the negative impact of FDI becomes smaller and smaller. Therefore, environmental regulation plays a significant role in weakening the "pollution haven" effect of FDI. In order to "screen" environmental friendly FDI, China should appropriately increase the strength of environmental regulation, raise the entry threshold, promote the technology spillover of FDI enterprises, so as to improve the environmental technology innovation ability of industrial enterprises. From the perspective of control variables, the impact of technological progress is negative, but not significant, which may be due to the significant difference between scientific research and technological development activities, and the impact of the two on technological innovation is also different ${ }^{[7]}$. If the difference is not made, it may be concluded that the increase of input level of scientific and technological innovation does not promote the significant improvement of China's total factor productivity ${ }^{[8]}$. The estimated coefficient of market demand pull is significantly positive, which indicates that market demand has a significant role in promoting environmental technology innovation. The estimation coefficient of industry scale is significantly positive, which indicates that the larger the industry scale, the greater the incentive for environmental technology innovation of industrial enterprises, which is consistent with Schumpeter's theory. By comparing the coefficients of various variables, we can see that the impact of market demand is the most obvious, which is also related to the strengthening of "informal environmental regulation". Therefore, the government should be the main force to accelerate the formation of market demand mechanism for environmental technology innovation. The regression results of each variable in model 4 and model 5 are similar to those in model 3, which proves the robustness of the model. 
Table 2. Panel model estimation results

\begin{tabular}{|c|c|c|c|c|c|}
\hline Variable & Model 1 & Model 2 & Model 3 & Model 4 & Model 5 \\
\hline $\ln r d$ & $\begin{array}{c}-0.575 \\
(-1.48)\end{array}$ & & $\begin{array}{c}-0.678^{*} \\
(-1.92)\end{array}$ & $\begin{array}{c}-0.366 \\
(-0.85)\end{array}$ & $\begin{array}{c}-0.680^{*} \\
(-1.73)\end{array}$ \\
\hline $\ln j s$ & $\begin{array}{c}0.135^{* *} \\
(1.73)\end{array}$ & & $\begin{array}{c}0.117^{*} \\
(1.70)\end{array}$ & $\begin{array}{c}0.278^{*} \\
(3.33)\end{array}$ & $\begin{array}{c}0.147^{* *} \\
(2.01)\end{array}$ \\
\hline $\ln z y$ & $\begin{array}{c}0.762^{*} \\
(2.57)\end{array}$ & & $\begin{array}{c}1.269^{* * *} \\
(6.31)\end{array}$ & $\begin{array}{c}1.219^{* * *} \\
(4.66)\end{array}$ & $\begin{array}{c}1.322^{* * *} \\
(6.16)\end{array}$ \\
\hline $\ln f d i_{-} 1$ & $-0.198^{* *}$ & $-0.169^{*}$ & $\begin{array}{c}-0.188^{* *} \\
(-2.22)\end{array}$ & $\begin{array}{c}-0.252^{* *} \\
(-2.14)\end{array}$ & $\begin{array}{c}-0.239^{* *} \\
(-2.43)\end{array}$ \\
\hline $\ln f d i_{-} 2$ & & $-0.085^{*}$ & $-0.169^{* *}$ & $\begin{array}{c}-0.203^{*} \\
(-1.69)\end{array}$ & $\begin{array}{c}-0.219^{* *} \\
(-2.19)\end{array}$ \\
\hline $\ln f d i_{-} 2$ & & $-0.061^{*}$ & $-0.095^{*}$ & $-0.103^{*}$ & $-0.146^{*}$ \\
$(-1.89)$ & $(-1.99)$ & $(-1.98)$ \\
\hline
\end{tabular}

Note: the values of $\mathrm{t}$ statistics in brackets; $* * *, * *$, and * are significant at $1 \%, 5 \%$ and $10 \%$ levels, respectively. Infdi_1 to lnfdi 3 are the estimation coefficients of FDI variables in different panel threshold intervals.

Furthermore, during the investigation period, the average level of environmental regulation in China is 4.3172, which has not yet entered the first threshold. FDI still has a great negative effect on environmental technology innovation of industrial enterprises. Specifically, in 2011, 22 provinces, autonomous regions and cities did not cross the first threshold, and only Hainan crossed the second threshold. By 2016, the environmental regulation intensity of most provinces, autonomous regions and cities has further increased, crossing the second threshold, and the blocking effect of FDI on technological innovation of industrial enterprises has further weakened. In addition, the intensity of environmental regulation in Ningxia has entered the third range.

\section{Conclusion}

The results of this paper show that FDI has a significant inhibitory effect on environmental technology innovation of industrial enterprises; the effect has a significant double threshold effect of environmental regulation; with the intensity of environmental regulation across the threshold, the negative impact of FDI is gradually weakened; market demand and industry scale also have a significant positive impact on environmental technology innovation of industrial enterprises in China, and the role of technological progress is not obvious.

Blind introduction of FDI may bring some negative effects on the environmental technology innovation of China's industrial enterprises, but when the intensity of environmental regulation is increased, the "screening" of FDI enterprises will be realized, and the enterprises will carry out technology spillover more rationally. The feedback results will be greatly improved in the aspects of science and technology content and green innovation through the absorption and digestion and even secondary innovation of domestic industrial enterprises. It has a positive impact on environmental technology innovation.
Therefore, the governments should strengthen the innovation of environmental regulation methods and the enforcement of regulations, and give full play to the positive role of FDI. In addition, we should attach importance to the role of non environmental regulation, build efficient communication mechanism and feedback channels $^{[6]}$, and increase the procurement of environmental protection products, so as to realize the pull of market demand on enterprise environmental technology innovation; industrial enterprises should appropriately expand the scale, introduce advanced technical equipment and scientific research personnel, undertake corporate social responsibility and increase environmental technology innovation.

\section{References}

1. Y.B. Zhang, P.Y. Pan, W. Lu, et al. Policy effects of environmental technology innovation in Chinese industrial enterprises $[\mathrm{J}]$. China population, resources and environment, 25,9: 138-144(2015).(in Chinese)

2. Blomstrm $\mathrm{M}$.and Kokko A.Multinational Corporations and Spill- overs[ J] .Journal of Economic Surveys, 12,3 :247-277(1998).

3. J.Y. Fu, J. Hu, X. Cao. FDI from different sources, environmental regulation and green total factor productivity [J]. International trade issues, 7: 134148(2018).(in Chinese)

4. X.B. Li. Empirical analysis on the change of regional innovation capability in China: Based on the perspective of innovation system [J]. Management world, 12: 18-30171(2007).(in Chinese)

5. N. Shen, F.C. Liu. Can high-intensity environmental regulation really promote technological innovation? -- a reexamination based on Porter hypothesis [J]. China soft science, 4: 49-59(2012).(in Chinese)

6. X.Y. Jiang, S. Zhao. Whether FDI suppresses carbon emission from the perspective of dual environmental regulation: An Empirical Study Based on GMM Estimation and threshold model of dynamic system $[\mathrm{J}]$. International trade issues, 3: 115-130(2019).(in Chinese)

7. X.S. Ye, J. Liu Heterogeneous R\&D, government support and China's technological innovation dilemma $[\mathrm{J}]$. Economic research,53,9: 116-132 (2018).(in Chinese)

8. W.B. Tang, Y.H. Fu, Z.X. Wang. Technological innovation, technology introduction and transformation of economic growth mode [J]. Economic research, 49,7: 31-43(2014).(in Chinese) 